\title{
STUDIES OF THE PULMONARY CIRCULATION. II. THE CIRCU- LATION TIME FROM THE PULMONARY ARTERY TO THE FEMORAL ARTERY AND THE QUANTITY OF BLOOD IN THE LUNGS IN PATIENTS WITH MITRAL STENO- SIS AND IN PATIENTS WITH LEFT VENTRICULAR FAILURE ${ }^{1,2}$
}

\author{
By CRAIG W. BORDEN, RICHARD V. EBERT, RUSSELL H. WILSON, \\ AND HERBERT S. WELLS \\ (From the Department of Medicine, University of Minnesota, and the Veterans \\ Administration Hospital, Minneapolis, Minn.)
}

(Received for publication February 21, 1949)

The pathogenesis of dyspnea in left ventricular failure and in mitral stenosis is not entirely understood but it is generally conceded that pulmonary vascular congestion is involved (1). Preceding the congestion there is probably an elevation in the left auricular and pulmonary venous pressures but to date it has not been possible to measure such pressures in the human being. Accurate quantitation of the pulmonary vascular congestion itself is difficult and the use of the vital capacity for this purpose is far from satisfactory. Much more promising in this connection is a method, described in a previous paper (2), which measures the volume of blood in the lungs, left heart, aorta, and certain systemic arteries. The method is based on the measurement of the mean circulation time from the pulmonary artery to the femoral artery, and the simultaneous determination of the cardiac output. An increased volume of blood in the pulmonary vessels should result in a corresponding increase in the total volume of blood $(Q)$ measured by the technique. The results of studies based on this premise are presented in the following account.

\section{MATERIAL AND METHODS}

A group of 10 men with rheumatic heart disease and mitral stenosis were studied. All these patients had dyspnea on exertion and some degree of pulmonary hypertension. As examples of left ventricular failure, 18

1 Published with permission of the Chief Medical Director, Veterans Administration, who assumes no responsibility for the opinions expressed or conclusions drawn by the authors.

2 Presented in part at a meeting of The American Society for Clinical Investigation in Atlantic City, N. J., May 3, 1948. men with disease of the aortic valve or hypertensive heart disease were chosen. All had dyspnea on exertion and had suffered from several episodes of paroxysmal dyspnea in the past, but none were severely orthopneic at the time the study was performed. Two of the patients with rheumatic heart disease and two with left ventricular failure previously had evidence of right ventricular failure manifested by hepatomegaly, peripheral edema and an elevated systemic venous pressure.

A catheter was introduced into the pulmonary artery by the method of Cournand and co-workers (3). The mean circulation time from the pulmonary artery to the femoral artery was measured and the cardiac output was determined as previously described (2). The volume of blood in the pulmonary vessels, left heart, aorta, and iliac arteries, together with all the blood contained within the other branches of the aorta to points where dye arrives no later than it does at the femoral artery $(Q)$ was determined from Stewart's formula (4). The pressures in the pulmonary artery, right ventricle, and right auricle were measured with a Hamilton manometer. The level of the right auricle was determined by the method of Lyons, Kennedy, and Burwell (5). The pulmonary arterial diastolic pressure was measured immediately before auricular systole to avoid artifacts which occur in the pulmonary arterial tracing during auricular systole. The systolic pressure was determined from the right ventricular tracing, since artifacts due to motion of the catheter interfered with this measurement in the pulmonary arterial tracings.

Heart volumes were determined from the teleroentgenogram by the method of Keys et al. (6). The predicted normal frontal area of the heart for the individual was estimated from the nomogram of Ungerleider and Gubner (7). The predicted heart volume was obtained by the use of the tables of Keys et al. (6).

The vital capacity was measured in the sitting position with a spirometer. The predicted normal figure for the individual was obtained by applying the formula of Baldwin, Cournand, and Richards (8). Four and fourtenths per cent were added to the value obtained by this formula to correct for the difference between the supine and sitting position (9). 


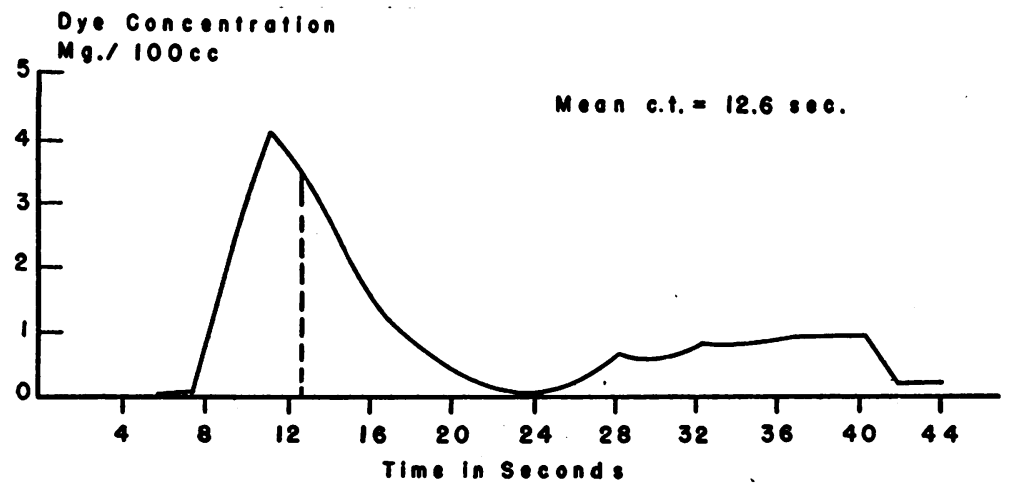

(a)

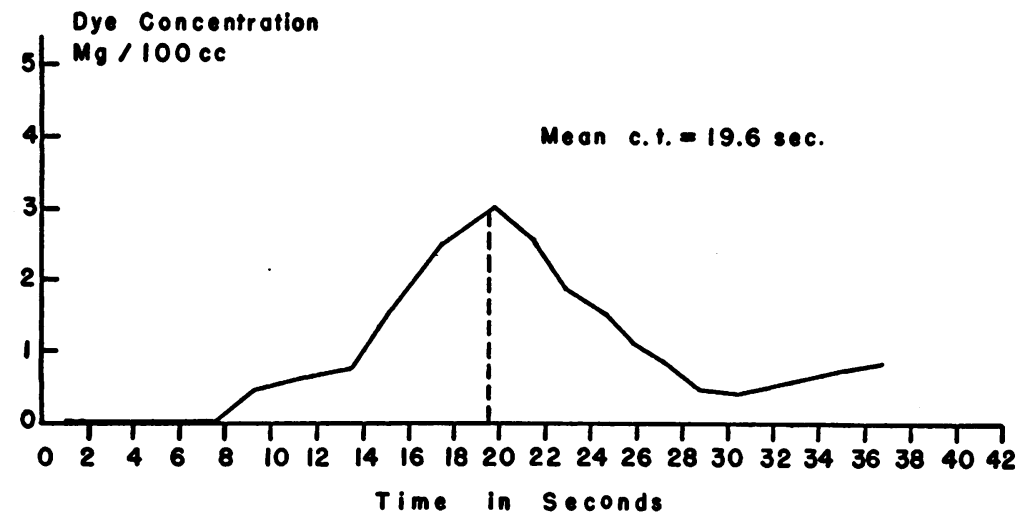

(b)

Fig. 1. Dye Concentration Curves in Patients with Heart Disease

(a) The chart above is the dye concentration curve in a patient with mitral stenosis (Subject R. C.), and (b) the chart below is the dye concentration curve in a patient with left ventricular failure (Subject J. K.).

TABLE I

Cardiac output, mean circulation time and $Q$ in a group of patients with rheumatic heart disease and mitral stenosis

\begin{tabular}{|c|c|c|c|c|c|c|c|c|c|c|c|c|c|}
\hline Subject & $\begin{array}{l}\text { Surface } \\
\text { area }\end{array}$ & $\begin{array}{l}\text { Oxygen } \\
\text { con- } \\
\text { sumed }\end{array}$ & $\begin{array}{c}\text { Arterio- } \\
\text { venous } \\
\text { oxygen } \\
\text { diff. }\end{array}$ & $\begin{array}{l}\text { Cardiac } \\
\text { output }\end{array}$ & $\begin{array}{c}\text { Cardiac } \\
\text { index }\end{array}$ & $\begin{array}{c}\text { Mean } \\
\text { circu- } \\
\text { lation } \\
\text { time }\end{array}$ & \begin{tabular}{|} 
Duration \\
of curve
\end{tabular} & $Q$ & $\begin{array}{l}\text { Total } \\
\text { blood } \\
\text { volume }\end{array}$ & $\begin{array}{l}\text { Vital } \\
\text { capacity }\end{array}$ & $\begin{array}{l}\text { Pulm. } \\
\text { arter. } \\
\text { press. } \\
\text { systolic }\end{array}$ & $\begin{array}{l}\text { Pulm. } \\
\text { arter. } \\
\text { press. } \\
\text { diastolic }\end{array}$ & $\begin{array}{l}\text { Right } \\
\text { ventric. } \\
\text { press. } \\
\text { diastolic }\end{array}$ \\
\hline $\begin{array}{l}\text { J. K. } \\
\text { H. H. } \\
\text { M. O. } \\
\text { V. S. } \\
\text { M. M. } \\
\text { E. M. } \\
\text { F. M. } \\
\text { L. N. } \\
\text { R. C. } \\
\text { G. W. }\end{array}$ & $\begin{array}{r}\text { sq. } m . \\
1.58 \\
1.69 \\
1.70 \\
1.74 \\
1.77 \\
1.77 \\
1.77 \\
1.79 \\
1.84 \\
1.93\end{array}$ & $\begin{array}{c}c c . / m i n . \\
220 \\
245 \\
253 \\
206 \\
284 \\
286 \\
272 \\
242 \\
249 \\
270\end{array}$ & 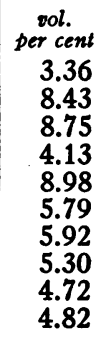 & \begin{tabular}{|r} 
L. $/$ min. \\
6.55 \\
2.91 \\
2.89 \\
4.99 \\
3.16 \\
4.94 \\
4.59 \\
4.57 \\
5.28 \\
5.60
\end{tabular} & \begin{tabular}{|c}
$L . / \min . /$ \\
sq. $m$. \\
4.15 \\
1.72 \\
1.70 \\
2.87 \\
1.79 \\
2.79 \\
2.59 \\
2.55 \\
2.87 \\
2.90
\end{tabular} & $\begin{array}{r}\text { sec. } \\
9.2 \\
24.1 \\
33.4 \\
13.6 \\
21.7 \\
15.7 \\
19.6 \\
14.0 \\
12.6 \\
13.5\end{array}$ & $\begin{array}{l}\text { sec. } \\
14.2 \\
26.0 \\
452 \\
17.4 \\
32.7 \\
22.0 \\
26.1 \\
13.2 \\
17.8 \\
20.0\end{array}$ & $\begin{array}{c}c c . \\
1000 \\
1170 \\
1610 \\
1130 \\
1140 \\
1290 \\
1500 \\
1070 \\
1110 \\
1260\end{array}$ & $\begin{array}{c}c c . \\
5340 \\
7726 \\
\overline{5060} \\
\overline{7710} \\
5000 \\
7200 \\
6510 \\
6930\end{array}$ & $\begin{array}{r}\text { per cent } \\
\text { normal } \\
95.5 \\
57.2 \\
60.4 \\
102.8 \\
47.8 \\
86.8 \\
50.4 \\
52.9 \\
79.3 \\
89.3\end{array}$ & \begin{tabular}{|c|}
$m m . H g$. \\
31.9 \\
83.5 \\
83.5 \\
33.6 \\
78.1 \\
43.0 \\
113.5 \\
64.0 \\
68.0 \\
40.4
\end{tabular} & $\begin{array}{r}\text { mm. Hg. } \\
15.6 \\
38.5 \\
36.2 \\
16.5 \\
46.0 \\
20.3 \\
61.7 \\
43.0 \\
31.0 \\
22.3\end{array}$ & $\begin{array}{r}\text { mm. Hg. } \\
1.7 \\
5.9 \\
13.8 \\
6.9 \\
1.4 \\
6.1 \\
8.6 \\
7.3 \\
1.0 \\
2.8\end{array}$ \\
\hline Mean & 1.76 & 253 & 6.02 & 4.55 & 2.59 & 17.7 & 23.5 & 1230 & - & 71.2 & 64.0 & 33.1 & 5.6 \\
\hline $\begin{array}{l}\text { Standard } \\
\text { deviation }\end{array}$ & \pm 0.10 & \pm 26 & \pm 2.01 & \pm 1.22 & \pm 0.74 & \pm 7.1 & \pm 9.7 & \pm 190 & - & \pm 19.0 & \pm 27.6 & \pm 14.9 & \pm 3.9 \\
\hline
\end{tabular}




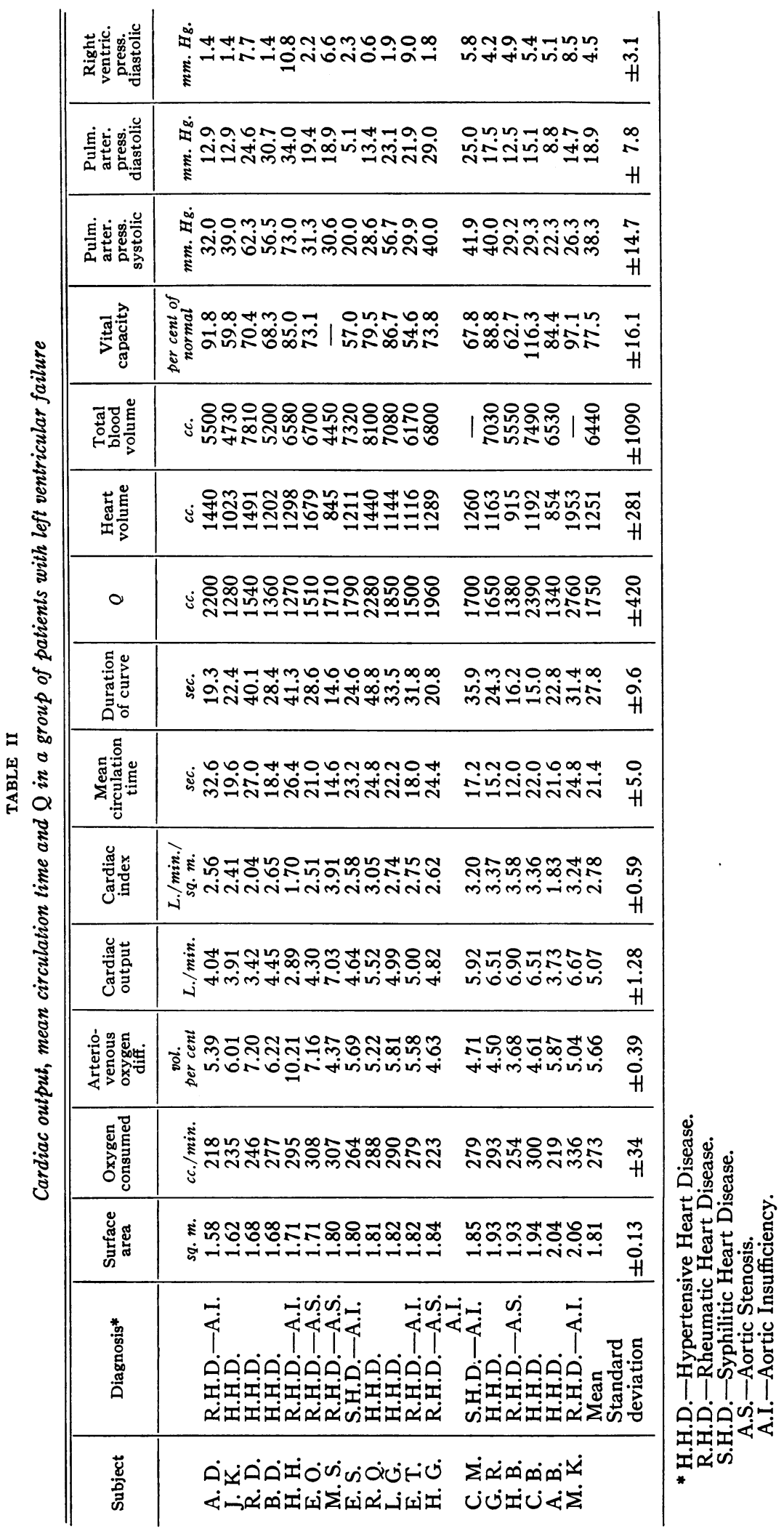




\section{RESULTS}

In order to determine the significance of the findings in the patients with heart disease it was necessary to compare them with the findings previously obtained in a group of 12 normal subjects (2). The dye concentration curves in patients with heart disease differed in most instances from the normal curve in that they were more prolonged than the normal and the maximal dye concentration was lower in the former than in the latter (Figure 1). Because recirculation usually began before the completion of the primary curve, a small error may have occurred in the determination of the mean circulation time. The mean circulation time was prolonged in the group with mitral disease and in the group with left ventricular failure, the increase being greater in the latter group (Table I). The mean cardiac index was significantly reduced in both groups as compared with the normal subjects.

The mean value for $Q$ in 10 patients with mitral stenosis was $1230 \mathrm{cc}$. as compared with $1160 \mathrm{cc}$. in the group of 12 normal subjects ([2] Table I). This difference is not significant statistically. Adjusting the individual values to $1.73 \mathrm{sq}$. m. body surface resulted in a larger difference between the two means but the statistical significance of the difference remained doubtful.

The mean value for $Q$ in the group of 18 patients with left ventricular failure was $1750 \mathrm{cc}$. which is

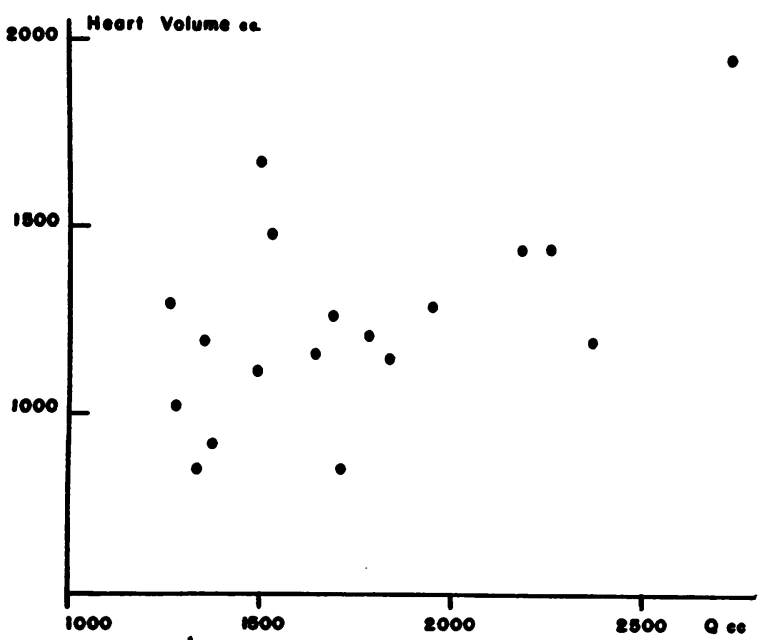

Fig. 2. Chart Showing Correlation Between Heart Volume and $Q$ in Patients with Left VenTRICULAR FAILURE
TABLE III

Comparison of mean increase in $Q$ with mean increase in volume of the heart in 18 patients with left ventricular failure

\begin{tabular}{l|c|c|c}
\hline & $\begin{array}{c}\text { Left } \\
\text { ventricular } \\
\text { failure }\end{array}$ & $\begin{array}{c}\text { Predicted } \\
\text { normal }\end{array}$ & $\begin{array}{c}\text { Mean } \\
\text { increase }\end{array}$ \\
\hline $\begin{array}{l}\text { Volume of heart (cc.) } \\
\begin{array}{l}\text { Estimated from } \\
\text { teleroentgenogram }\end{array}\end{array}$ & 1251 & 675 & 576 \\
$Q$ (cc.) & 1750 & 1160 & 590 \\
\hline
\end{tabular}

significantly greater than the mean value for $Q$ in normal subjects (Table II). It was immediately apparent that the increase in $Q$ in the group with left ventricular failure could be due to an increase in volume of blood in the left ventricle. In order to evaluate this possibility, the volume of the heart in the individual cases was plotted against $Q$ (Figure 2). There was a moderate correlation $(r=0.6954 \mathrm{p}<.01)$. In Table III the difference between the mean volume of the heart in the group with left ventricular failure and the predicted mean normal heart volume for the group is compared with the difference between the mean value for $Q$ in the group with left ventricular failure and the mean value for $Q$ in the group of normal subjects. The two values were very similar.

The pulmonary arterial pressure was moderately elevated in the group with left ventricular failure and more strikingly elevated in the group with mitral stenosis (Tables I and II). There was no correlation between $Q$ and the vital capacity in either group.

\section{DISCUSSION}

The prolongation of the circulation time from a peripheral vein to an artery in heart disease is well known and is widely used in the clinical assay of congestive heart failure. In most studies of the circulation time, a method is used which gives a single end point. The means of detecting the end point differs, both in technique and in sensitivity, from method to method. For example, in the determination of the circulation time by the use of radium as performed by Blumgart and Weiss (10), the end point depends on the sensitivity of the detecting device and the concentration of the radium in the blood flowing through the brachial artery. Hamilton et al. (11) have demonstrated that this end point does not represent the mean 
circulation time but merely approximates the earliest circulation time. A study of the dye concentration curve determined in patients with heart disease, makes it apparent that the measurement of the circulation time by the usual method will give a value which is quite remote from the true mean circulation time.

The importance of the determination of the mean circulation time lies in the fact that it is a function of the rate of blood flow and the volume of blood contained in a given portion of the circulation. According to Stewart (4) and Hamilton (11), the mean circulation time from the pulmonary artery to the left auricle should be inversely proportional to the cardiac output and directly proportional to the volume of blood in the pulmonary vessels. Unfortunately, it is impossible to measure the circulation time from the pulmonary artery to the left auricle so that this approach to the estimation of the pulmonary blood volume is closed. It is possible, however, to measure the mean circulation time from the pulmonary artery to the femoral artery. Using Stewart's formula, one finds that this mean circulation time is inversely proportional to the cardiac output and directly proportional to the value $Q$, which represents the amount of circulating blood in the lungs, left heart, aorta, and certain other arteries as defined above. Hence, if the cardiac output and the mean circulation time are known, $Q$ can be calculated. If the volume of blood in the aorta and left heart remains constant, variations in the pulmonary blood volume will cause corresponding variations in $Q$. Blood in the lungs which is stagnant or circulating very slowly would not be measured by this method.

There was no significant increase in $Q$ in the group of patients with mitral stenosis and pulmonary hypertension as compared with the group of normal subjects, and it can be concluded, therefore, that there was no large increase in pulmonary blood volume. Moreover, a marked increase in pulmonary arterial pressure can occur in mitral stenosis without an increase in $Q$ and, consequently, without a large increase in pulmonary blood volume. None of the patients studied had severe orthopnea or evidence of pulmonary congestion and edema roentgenologically. It is quite possible that a marked increase in pulmonary blood volume does occur in patients with these findings.

There was a marked increase in $Q$ in the group of patients with left ventricular failure. Gernandt and Nylin (12) have observed a relationship between increase in circulation time from peripheral vein to peripheral artery and increase in size of the heart. All patients with left ventricular failure in this study had varying degrees of left ventricular enlargement, and the largest increase in $Q$ occurred in those patients with the largest hearts. A positive correlation existed between the heart volume and $Q$. If the mean increase in heart volume is compared with the mean increase in $Q$, the similarity of the two values suggests that they have a common cause, namely, an increase in the amount of blood in the left ventricle. In roentgenological studies of heart volume, it is impossible to distinguish between the effects of hypertrophy and dilatation but it is generally conceded that the increase in the size of the heart in heart failure is primarily due to cardiac dilatation $(13,14)$. Because of the contribution of the blood in the dilated left ventricle to $Q$, it is difficult to evaluate changes in pulmonary blood volume in patients with left ventricular failure.

The reduction in vital capacity in patients with heart disease has been attributed to pulmonary congestion with consequent changes in pulmonary distensibility and elasticity $(15,16)$. It has been suggested that prolongation of the circulation time in association with reduced vital capacity is due to an increase in the volume of blood in the lungs (17). From the present study, it does not appear that reduction of vital capacity is of necessity accompanied by a large increase in pulmonary blood volume, nor does it appear that an increase in pulmonary blood volume is the major factor in prolonging the circulation time.

\section{SUMMARY AND CONCLUSIONS}

1. The mean circulation time from the pulmonary artery to the femoral artery and cardiac output were determined on 10 patients with mitral stenosis associated with pulmonary hypertension and 18 patients with left ventricular failure.

2. From the mean circulation time and the cardiac output the volume of blood in the pulmo- 
nary vessels, left heart, aorta and certain other arteries $(Q)$ was calculated.

3. The mean circulation time was prolonged and the cardiac output was reduced in both groups as compared with normal subjects. The value for $Q$ in the group of patients with mitral stenosis and pulmonary hypertension did not differ significantly from the value in normal subjects and hence, there was no evidence of a large increase in circulating blood in the lungs.

4. A marked increase in $Q$ was present in the group of patients with left ventricular failure. Because of evidence which suggested that the increase in $Q$ was largely due to an increase in the amount of blood in the left ventricle, it was impossible to evaluate changes in pulmonary blood volume in this group.

5. There was no correlation between the reduction in vital capacity and $Q$. This suggests that the reduction in vital capacity in patients with heart disease is not a direct function of increase in pulmonary blood volume.

\section{BIBLIOGRAPHY}

1. Harrison, T. R., Failure of the Circulation. The Williams \& Wilkins Company, Baltimore, 1939.

2. Ebert, R. V., Borden, C. W., Wells, H. S., and Wilson, R. H., Studies of the pulmonary circulation. I. The circulation time from the pulmonary artery to the femoral artery and the quantity of blood in the lungs in normal individuals. J. Clin. Invest., 1949, 28, 1134.

3. Cournand, A., Riley, R. L., Breed, E. S., Baldwin, E. deF., and Richards, D. W., Jr., Measurement of cardiac output in man using the technique of catheterization of the right auricle or ventricle. J. Clin. Invest., 1945, 24, 106.

4. Stewart, G. N., The pulmonary circulation time, the quantity of blood in the lungs and the output of the heart. Am. J. Physiol., 1921, 58, 20.
5. Lyons, R. H., Kennedy, J. A., and Burwell, C. S., The measurement of venous pressure by the direct method. Am. Heart J., 1938, 16, 675.

6. Keys, A., Friedell, H. L., Garland, L. H., Madrazo, M. F., and Rigler, L. G., The roentgen kymographic evaluation of the size and function of the heart. Am. J. Roentgenol., 1940, 44, 805.

7. Ungerleider, H. E., and Gubner, R., Evaluation of heart size measurements. Am. Heart J., 1942, 24, 494.

8. Baldwin, E. de F., Cournand, A., and Richards, D. W., Jr., Pulmonary insufficiency. Medicine, 1948, 27, 243.

9. Kaltreider, N. L., Fray, W. W., and Hyde, H. v. Z., The effect of age on the total pulmonary capacity and its subdivisions. Am. Rev. Tuberc., 1938, 37, 662.

10. Blumgart, H. L., and Weiss, S., Studies on the velocity of blood flow. VII. The pulmonary circulation time in normal resting individuals. J. Clin. Invest., 1927,4, 399.

11. Hamilton, W. F., Moore, J. W., Kinsman, J. M., and Spurling, R. G., Studies on the circulation. IV. Further analyses of the injection method, and of changes in the hemodynamics under physiological and pathological conditions. Am. J. Physiol., 1932, 99, 534.

12. Gernandt, B., and Nylin, G., The relation between circulation time and the amount of the residual blood in the heart. Am. Heart J., 1946, 32, 411.

13. Sussman, M. L., in Clinical Radiology, edited by Pillmore, G. U. F. A. Davis Company, Philadelphia, 1946, Vol. 1, p. 33.

14. White, P. D., Heart Disease, 3rd Edition, The Macmillan Company, New York, 1944, p. 583.

15. Peabody, F. W., and Wentworth, J. A., Clinical studies of the respiration. IV. The vital capacity of the lungs and its relation to dyspnea. Arch. Int. Med., 1917, $20,443$.

16. Christie, R. V., and Meakins, J. C., The intrapleural pressure in congestive failure and its clinical significance. J. Clin. Invest., 1934, 13, 323.

17. Blumgart, H. L., The velocity of blood flow in health and disease. The velocity of blood flow in man and its relation to other measurements of the circulation. Medicine, 1931, 10, 1. 